\title{
Formas de vida e jogos de linguagem: a Etnomatemática como método de pesquisa e de ensino
}

\author{
Isabel Cristina Machado de Lara
}

\section{Resumo}

Este artigo objetiva apontar diferentes possibilidades acerca da operacionalização da Etnomatemática como método de pesquisa e ensino na Educação Básica, por meio do reconhecimento de jogos de linguagem que constituem diferentes saberes matemáticos. Delineia a trajetória teórica do Grupo de Estudos e Pesquisas em Etnomatemática - GEPEPUCRS - desde sua constituição, revisita principais autores que tratam da Etnomatemática e traz à tona condições criadas pelos estudos de Wittgenstein (2014) para pensar em diferentes formas de matematizar a partir de distintos usos que se faz da Matemática. Levando em conta os estudos kantianos acerca da aquisição do conhecimento, é possível fazer uma analogia entre a faculdade de intuir, a faculdade do entendimento e a faculdade de julgar com os passos sugeridos por Ferreira (2003) em relação à Etnomatemática como recurso pedagógico. Diante disso, propõem uma concepção de Etnomatemática a partir dessas perspectivas e delineia as etapas que possibilitam sua operacionalização como método de pesquisa e de ensino em sala de aula.

Palavras-chave: Etnomatemática. Método de ensino. Jogos de linguagem. 


\title{
Forms of life and language games: the Etnomatemática as a method of research and teaching
}

\author{
Isabel Cristina Machado de Lara
}

\begin{abstract}
This article intends to point out different possibilities about the operationalization of Ethnomathematics as a method of research and teaching in Basic Education, through the recognition of language games that constitute different mathematical knowledge. It outlines the theoretical trajectory of the Group of Studies and Research on Ethnomathematics GEPEPUCRS - since its formation, revisits leading authors dealing with ethnomathematics and brings to surface conditions created by Wittgenstein's (2014) studies to think of different ways of mathematizing from different uses that is made of it. . Taking into account the Kantian studies about the acquisition of knowledge,, it is possible to make an analogy between a faculty of intuition, a faculty of understanding and a faculty of judging with the steps suggested by Ferreira (2003) in relation to Ethnomathematics as a pedagogical resource. Therefore, a conception of ethnomathematicsis proposed in these perspectives and outlines the steps that enable its operation as a method of research and teaching in the classroom.
\end{abstract}

Keywords: Ethnomathematics. Teaching Method. Language Games. 


\section{Introdução}

Nos encontramos em um cenário onde a globalização, ao lado das tecnologias de informação e comunicação, possibilitam um repensar nas questões a respeito do trabalho, da propriedade e do ensino. Enquanto muitos pesquisadores já discutiam, no século XX e início do século XXI, a emergência de uma sociedade de controle, da informação, do conhecimento, de uma "Era do Acesso", vivemos ainda, principalmente no âmbito escolar, princípios de uma sociedade disciplinar (LARA, 2001). Efeito disso, é o pensar disciplinar e o "poder disciplinador” exercido, em particular, pela Matemática Acadêmica (LARA, 2001). Contudo, se queremos dar conta de situações apresentadas pelo atual contexto, no ensino da Matemática, torna-se necessário outro modo de olhar, de refletir e de pensar, um modo de pensar transdisciplinar.

Foi com essa percepção inicial que, em 2012, institui-se o Grupo de Estudos e Pesquisa em Etnomatemática na Pontifícia Universidade Católica do Rio Grande do Sul - GEPEPUCRS. Os estudos e pesquisas que vêm sendo desenvolvidos pelo grupo buscam refletir sobre os deslocamentos que as concepções acerca da Etnomatemática vem realizando nos últimos anos, tendo como foco desenvolver pesquisas que utilizem a Etnomatemática como um método de pesquisa e de ensino.

A Matemática que aprendemos e ensinamos nas escolas, considerada como conhecimento matemático legitimado, ou Matemática Escolar advinda da Matemática Acadêmica, tem suas origens na antiguidade mediterrânea, produzida historicamente há mais de 3000 anos. D’Ambrosio propõe o Programa Etnomatemática o qual “[...] repousa sobre uma análise das diferentes teorias e práticas matemáticas em diversos ambientes culturais” (2004, p. 18), não no sentido de ignorar ou rejeitar a Matemática Acadêmica, atravessada pelo conhecimento e pelo comportamento moderno, mas no sentido de aprimorar tal conhecimento, conhecê-lo visando uma ética de respeito, solidariedade e cooperação.

Com esse olhar, o autor define o Programa Etnomatemática como “[...] um programa que visa explicar os processos de geração, organização e transmissão de conhecimento em diversos sistemas culturais e as forças interativas que agem nos e entre os três processos.” (D’AMBROSIO, 1993, p.7).

Nesse sentido, é possível pensar a Etnomatemática como um método de pesquisa e de ensino que cria condições para que o estudante reconheça e compreenda o modo como um saber matemático foi gerado, organizado e difundido dentro de determinados grupos culturais. Tal compreensão possibilitará uma reflexão acerca de saberes ${ }^{1}$ que foram ou não legitimados

\footnotetext{
${ }^{1}$ Vale ressaltar que, neste estudo, é feita uma distinção entre o significado das palavras saber e conhecimento, do mesmo modo que Veiga-Neto e Nogueira (2010), chama-se atenção para os estudos feitos por Wittgenstein, em sua segunda fase, afirmando que o significado da palavra é determinado pelo uso que fazemos dela. Além disso, uma
} ISSN 2526-2882 
na perspectiva da Matemática Escolar. Desse modo, ao investigar concepções, tradições e práticas matemáticas de um determinado grupo cultural, a intenção é de incorporá-las ao currículo escolar. Adicionado a isso, tem-se a definição de Barton: “A Etnomatemática é uma tentativa de descrever e entender as formas pelas quais ideias, chamadas pelos etnomatemáticos de matemáticas, são compreendidas, articuladas e utilizadas por outras pessoas que não compartilham da mesma concepção de "matemática”." (2006, p. 55). Tal modo de tratar a Etnomatemática possibilita identificar saberes, designados saberes matemáticos presentes em distintos grupos culturais.

Em Investigações Filosóficas, Wittgenstein ${ }^{2}$ aponta questões essenciais para pensarmos a Educação Matemática, em particular, numa perspectiva da Etnomatemática. Para o filósofo “[...] o significado de uma palavra é seu uso na linguagem." (WITTGENSTEIN, 2014, p. 38), ou seja: "A significação de uma palavra é dada a partir do uso que dela fazemos em diferentes situações e contextos." (CONDÉ, 1998, p. 89) no interior de um jogo de linguagem. Condé (2004) destaca que tal jogo é "[...] regido por regras que distinguem o uso correto ou incorreto das palavras nos diversos contextos.”, além disso, explica que uma mesma expressão linguística pode assumir diferentes significações dependendo do uso que se faz dela. Ao negar a existência de uma linguagem universal, Wittgenstein (2014) possibilita refutar a linguagem matemática universal permitindo pensar em diferentes matemáticas, “[...] geradas em diferentes formas de vida - que podem ser entendidas como jogos de linguagem que possuem determinados parentescos e não encontram-se totalmente incomunicáveis uns com os outros.” (KROETZ; LARA, 2016, p. 246).

A partir dessas teorizações o grupo de estudos GEPEDPUCRS vem se constituindo e desenvolvendo diferentes investigações. Assim, o objetivo deste texto é apontar distintas possibilidades acerca da operacionalização da Etnomatemática como método de pesquisa e de ensino na Educação Básica, por meio do reconhecimento de jogos de linguagem que constituem diferentes saberes matemáticos.

\section{Trajetória teórica do grupo de pesquisa}

$\mathrm{O}$ foco de muitas discussões acadêmicas e de eventos ${ }^{3}$ em diversas áreas tem sido, ainda na primeira década do século XXI, a questão da diversidade. Nesses últimos anos, é

palavra admite infinitas interpretações, e "[...] sempre será possível dizer algo ainda não dito, pensar algo ainda não pensado." (VEIGA-NETO; NOGUEIRA, 2010, p. 71). Nesse contexto, saberes são subjetivos, resultados de diferentes práticas discursivas, enquanto conhecimento refere-se a uma objetividade, a existência do certo e do errado, de relações e regularidades de algo que não é subjetivo.

${ }^{2}$ Ludwig Wittgenstein (1889 - 1951).

3 O Congresso Nacional de Diversidade e Inclusão - CONADI, é um evento anual que teve sua primeira edição realizada em 2008. Congresso Nacional Educação e Diversidade, $1^{a}$ edição em 2011; Congresso Nacional de Diversidade, Ética, Direitos Humanos, 2 a edição em 2011; Congresso Internacional de Gestão da Diversidade Linguística e Cultural na Educação; Simpósio sobre Evolução e Diversidade, $1^{\mathrm{a}}$ edição em 2010, entre outros. ISSN 2526-2882 
possível perceber que não só a sociedade mudou, como é possível observar cada vez mais indivíduos diversos, categorias diferentes de pessoas, que como afirma Foucault 4 (2003, p. 268), nem sempre estão submetidos à disciplina ${ }^{5}$.

Nesse sentido, é possível citar Walkerdine (1995) ao questionar as "metanarrativas da ciência", nas quais o "pensamento abstrato" é o pináculo do ser civilizado e o "raciocínio 'abstrato' deixa de levar em conta a produção do pensamento nas práticas reais”. Para ela é preciso destruir a fantasia do "sonho da razão" e das metanarrativas da ciência ligadas ao projeto burguês europeu, reconhecendo que a produção do pensamento se dá nas práticas, estando repleta de significados e emoções complexas.

D’Ambrosio ao propor o Programa Etnomatemática e ao denominar a disciplina Matemática como uma etnomatemática, é possível perceber uma convergência de seu pensamento às ideias de Walkerdine no que se refere à produção do pensamento em diferentes práticas. Contudo, conforme Lara (2001) afirma:

\begin{abstract}
Mesmo com a universalidade da Matemática relativizada pelos discursos mais atuais da área, a Matemática Acadêmica - ou, se se quiser, a Matemática Formal constituída pelo discurso moderno ocidental - continua sendo utilizada como instrumento de seleção para, praticamente, todas as áreas de estudo ou trabalho, e não somente para o acesso a posições que, necessariamente, exigem seu conhecimento como pré-requisito. (p.25).
\end{abstract}

Isso se justifica, pois conforme Pessanha (1997): "Elegemos um discurso como sendo o legítimo, o científico e o verdadeiro." (p. 15), porém, “[...] há outros discursos, outras maneiras também racionais de se falar a verdade.” (p. 15). No caso da Matemática Acadêmica é possível utilizar as palavras de Pessanha, como sendo: "Algo que se configurou, afirmou, sacramentou e se solidificou de tal maneira que não percebemos que é uma tradição. Pensamos que as coisas são assim porque são, e que fatalmente sempre serão da mesma maneira.” (1997, p.15).

Em sua pesquisa Lara (2001) analisou a constituição histórica de diferentes concepções acerca do ensino da Matemática no Brasil, evidenciando que existem dois principais discursos cujos pressupostos são apresentados como verdadeiros:

- por um lado, uma Matemática exata, pronta, absoluta, universal, ahistórica, atemporal e incontingente[...];

\footnotetext{
4 Michel Foucault (1926-1984).

5 As disciplinas são consideradas por Foucault (1989, p. 126) como "[...] métodos que permitem o controle minucioso das operações do corpo, que realizam a sujeição constante de suas forças e lhe impõem uma relação de docilidade-utilidade". Para ele, a disciplina é vista tanto como um sistema de controle quanto um campo de estudo. Dessa forma, a disciplina compreende dois eixos: o cognitivo, atrelado à disciplina-saber, e o corporal atrelado à disciplina-corpo.
} 
- por outro lado, uma Matemática "viva”, em constante "evolução", cujos resultados são provisórios e relativos, já que está contextualizada e direcionada a situações reais e atuais [...]. (LARA, 2001, p. 27).

Contudo, o primeiro discurso ainda é hegemônico em muitas escolas, o que reforça a necessidade de pensarmos na Etnomatemática como um método de ensino, no sentido de criar condições de possibilidades para que os saberes matemáticos produzidos em diferentes formas de vida possam ser inseridos no currículo escolar no intuito de colocar sob suspeita o conhecimento e o comportamento moderno, visando assim como afirma D’Ambrosio (2002), “[...] aprimorá-los [comportamento e conhecimento], incorporando a ele valores da humanidade, sintetizados numa ética de respeito, solidariedade e cooperação.” (p. 43).

Há décadas, a Etnomatemática é considerada como uma tendência da Educação Matemática consolidada como um método de pesquisa. Assim, no início das investigações desenvolvidas pelo grupo, partia-se dessa perspectiva. Contudo, ampliando o campo teórico, cria-se condições para compreender o modo como foi sendo constituída como método de pesquisa etnográfica e como é possível operacionalizá-la como um método de ensino de Matemática na Educação Básica.

\section{A emergência da Etnomatemática: algumas concepções}

De acordo com Ferreira (2003), o fracasso do Movimento da Matemática Moderna MMM - desencadeou diferentes discursos e correntes educacionais que tinham em comum “[...] a forte reação contra a existência de um currículo comum e contra a maneira imposta de apresentar a matemática de uma só visão, como um conhecimento universal e caracterizado por divulgar verdades absolutas.” (p. 3). Além disso, a constatação de que o conhecimento prévio, de cunho social, do estudante não era considerado em sala de aula fez com que esses educadores matemáticos voltassem seus estudos para esse tipo de conhecimento.

Além disso, as dificuldades de aprendizagem de estudantes de classes menos favorecidas instigaram educadores a se dedicarem aos estudos dos aspectos socioculturais da Educação Matemática. Emergem, a partir daí, pesquisas que se utilizam de diferentes termos para designar esta Matemática que ocorre fora do contexto escolar. Embora os termos sejam diversos, algumas vezes, os contextos em que são aplicados convergem. Gerdes (2002) e Ferreira (2003) apresentam essa trajetória em seus estudos começando com Zaslavski, que em 1973, conforme Ferreira (2003), utilizou o termo Sociomatemática em suas pesquisas com povos africanos.

Ferreira encerra sua cronologia com D’Ambrosio, que mesmo publicando o termo Etnomatemática pela primeira vez em 1985, no artigo intitulado Ethnomathematicsand its Place in the History and Pedagogy of Mathematics, desenvolveu estudos desde 1970 e utilizou 
o termo, de acordo com Rosa e Orey (2014), pela primeira vez em 1977 em uma palestra realizada no Annual Meeting of the American Association for the Advancementof Science, em Denver, nos Estados Unidos. A consolidação internacional do Programa Etnomatemática foi feita como o International Study Group on Ethnomathematics (ISGEm), criado em 1985 (ROSA; OREY, 2014). Em uma entrevista à Revista Carta Capital, em 2007, D’Ambrosio conta que:

Na década de 1960, durante o período militar, eu morava nos Estados Unidos e fui convidado para dar aula de doutorado na África, num projeto da Unesco. Passava duas ou três semanas lá e voltava. Fui conhecendo a cultura dos africanos e percebi que a Matemática avançada que eu lhes ensinava não tinha nada a ver com o contexto cultural em que eles viviam. Ao mesmo tempo, via que as cidades estavam carregadas de uma Matemática que não era aquela européia, ensinada na academia e nas escolas. Depois, viajando pela América Latina, tive a certeza de que meu sentimento era correto: não existe uma Matemática única. Vide Machu Picchu, no Peru, uma cidade construída com técnicas de urbanismo e que resistia a terremotos. Isso é Matemática da cultura inca.

Conforme Ferreira (2003), em 1986, foi criado o Grupo Internacional de Estudo em Etnomatemática - IGSEm, constituído por pesquisadores educacionais de diferentes partes do mundo, preocupados com essa temática e como utilizá-la em sala de aula. Ao se referir ao termo Etnomatemática, Ferreira afirma que: "Em primeiro lugar o prefixo Etno se refere à Etnia, isto é, a um grupo de pessoas de mesma cultura, língua própria, ritos próprios, etc., ou seja características culturais bem delimitadas para que possamos caracterizá-lo como um grupo diferenciado.” (2003, p.1). Ao considerar Etnomatemática o faz de modo semelhante à Etnociências, “[...] que propõe a redescoberta da ciência de outras etnias, que não a nossa cuja ciência advém da cultura ocidental. Etno, então, refere-se ao sistema de conhecimentos e cognições típicas de uma dada cultura.” (p.1).

Para D’Ambrosio (2002), cada indivíduo tem uma forma diferente de perceber a realidade, de receber e processar informações. Assim, o pensamento abstrato, próprio de cada indivíduo, é uma elaboração de representações da realidade e é compartilhado graças à comunicação, dando origem ao que denomina de cultura. Ou seja: "A associação, simbiótica, de conhecimentos compartilhados e de comportamentos compatibilizados constitui o que se chama de cultura.” (2002, p. 59). Para o autor: “A cultura se manifesta no complexo de saberes/fazeres, na comunicação, nos valores acordados por um grupo, uma comunidade ou um povo. Cultura é o que vai permitir a vida em sociedade.” (p. 59). D’Ambrosio dá à Etnomatemática um enfoque fundamentalmente holístico, procurando entender o saber/fazer matemático ao longo da história da humanidade, contextualizado em diferentes grupos. 
De acordo com Ferreira (2003), Paulus Gerdes ${ }^{6}$ também é um dos pioneiros na conceituação da Etnomatemática. Para Gerdes, “[...] cada povo - cada cultura e subcultura desenvolve a sua própria matemática, de certa maneira específica. A matemática é considerada, portanto, atividade universal." (2002, p.222).

Vale ressaltar que de acordo com Powell, existem duas vertentes importantes de Etnomatemática: a de Ubiratan D’Ambrosio e a de Márcia Ascher ${ }^{7}$ e Robert Ascher (FERREIRA, 2003, p. 11). Enquanto D'Ambrosio amplia a abrangência do conceito de etno para grupos culturais identificáveis entendidos como: “[...] sociedades nacionais, sociedades tribais, grupos sindicais e profissionais, crianças de uma certa faixa etária, etc.”, para Marcia e Robert Ascher: Ethnomathematicsisthestudyofnathematicalideasofnonliteratepeoples. Werecognize as mathematical thought notionst hat in some way correspond to that label in ourculture. For example, allhumans, literateornot, impose arbitrary or dersonspace. ${ }^{8}$ (1981, p. 26). Para os autores "[...] existem ideias matemáticas de povos não-letrados, mas não existe matemática, pois esta nasce do pensamento ocidental" (FERREIRA, 2003, p.12). Ascher e Ascher (1981, p.158-159) afirmam que:

In Western culture a professional class, called mathematicians,..., deals solely and exclusively with these concepts. Examples of other groups involved in mathematical endeavors are accountants, architects, bookies, construction engineers, landscape designers, navigators, and system analysts. Nonprofessional mathematics, as practiced by these groups... may often be implicit rather than explicit. 9

Uma concepção não exclui a outra, é perceptível que a perspectiva de Ascher e Ascher se insere na visão de D’Ambrosio uma vez que possui um cunho antropológico. Portanto, embora os primeiros estejam preocupados com grupos que possuem baixa escolarização, ambos se complementam. De acordo com Barton (2006), embora um e outro concordem quanto ao potencial da Etnomatemática dentro da educação, Ascher e Ascher buscam vitalizar a Matemática, enquanto D’Ambrosio, fortalecer a educação. D’Ambrosio (1988) ressalta que:

É importante lembrar que Márcia e Robert Ascher partem da conceituação da Etnomatemática como "o estudo das ideias matemáticas de povos não alfabetizados”, e fazem um apelo para que tal conceituação seja estendida, e

${ }^{6}$ PaulusGerdes (1953-2014).

7 Marcia Ascher (1935-2013).

8“[...] etnomatemática é o estudo de ideias matemáticas dos povos não-letrados. Reconhecemos como pensamento matemático noções que de algum modo correspondem às rotuladas em nossa cultura. Por exemplo, todos os humanos, letrados ou não, impõem ordens arbitrárias ao espaço" (ASCHER; ASCHER, 1997, p.26 apud MONTOITO, 2009, p. 77).

9 "Na cultura ocidental, uma classe profissional, chamada de matemáticos, ... trata única e exclusivamente desses conceitos. Exemplos de outros grupos envolvidos em desenvolvimentos matemáticos são contadores, arquitetos, bookies, engenheiros civis, paisagistas, navegadores e analistas de sistemas. A matemática não profissional, praticada por esses grupos ... muitas vezes pode ser implícita e não explícita.” (Tradução minha). ISSN 2526-2882 
que se libere da conotação de que tudo se resume a modos de contagem e de práticas de decoração. (s/p).

Ao abordar os distintos modos do saber e do fazer no cotidiano, D'Ambrosio (2002) refere-se à Etnomatemática não apreendida nas escolas, com uma conceitualização muito mais ampla. Ele destaca, que quando fala de cultura, não se refere apenas ao sentido de etnia, mas se volta também, para aquele saber/fazer matemático gerado no ambiente familiar, no ambiente dos brinquedos e do trabalho. Ou seja, usa o prefixo etno com uma concepção bem mais abrangente que a utilizada em Antropologia, restrita às raízes étnicas. O discurso da Etnomatemática apresentado por D’Ambrosio (2004) considera a transdisciplinaridade como um enfoque holístico ao conhecimento fundamentado no resgate das várias dimensões do ser humano para compreender, não apenas objetos de estudo bem definidos ou de estudos multidisciplinares ou interdisciplinares, mas sim, o mundo como um todo, na sua integralidade.

\section{Acerca da concepção de cultura e linguagem}

Em relação à definição de cultura, embora reconheça as ideias de D'Ambrosio, a maioria das pesquisas desenvolvidas no âmbito do grupo de pesquisa GEPEPUCRS, fundamenta-se nas teorizações de Tylor $^{10}$ (1871), Geertz ${ }^{11}$ (1989), Herskovits ${ }^{12}$ (1973) e Laplantine (2007). Conforme Laraia (2001), surgem, ao final do século XVIII, termos kultur e civilization ${ }^{13}$, que ao serem sintetizados num único - culture - por Edward Tylor, passa a ser definido como "[...] todo complexo que inclui conhecimentos, crenças, arte, moral, leis, costumes ou qualquer outra capacidade ou hábitos adquiridos pelo homem como membro de uma sociedade.” (TYLOR, 1871, p. 1). Com essa definição, de acordo com Laraia (2003), todas as possibilidades de realização humana foram abrangidas em uma só palavra, e após essa definição centenas de conceitos sobre cultura surgiram, o que acarretou na amplificação do seu significado e tornou-o confuso.

Devido à amplitude e dimensão que o conceito atingiu, Geertz (1989) destacou a necessidade de diminuir tal amplitude e reformulá-lo teoricamente. Com esse ajuste, o conceito traria outra vez uma conotação antropológica, realizando um estudo interpretativo da cultura e visando, como Lévi-Strauss ${ }^{14}$ (1970, p. 14) destaca, “[...] a reconstituição, tão fiel quanto possível, da vida de cada um deles.”.

\footnotetext{
${ }^{10}$ Edward Burnett Tylor (1832-1917).

${ }^{11}$ Clifford Geertz (1926-2006).

12 Melville Herskovits (1895-1963).

${ }^{13}$ De origem germânica, o primeiro termo era utilizado para a representação dos aspectos espirituais, já, o outro dizia respeito às concretizações materiais de determinado grupo.

14 Claude Lévi-Strauss (1908-2009).
}

ISSN 2526-2882 
Herskovits (1973), contudo, afirma em sua obra Antropologia Cultural, que embora existam diversas definições para cultura, todas convergem ao reconhecer que ela pode ser aprendida, permitindo adaptações ao ambiente natural, manifestando-se em modelos e artefatos. Para o autor, cada grupo possui peculiaridades em seu estilo de vida que apresenta traços originais, fazendo com que cheguem a soluções características de seu próprio grupo. Tais soluções são diferentes daquelas apresentadas pelos demais grupos.

Complementando essa ideia, apresenta-se a definição de cultura dada por Laplantine (2007) como sendo "[...] o conjunto dos comportamentos, saberes e saber-fazer característicos de um grupo humano ou de uma sociedade dada, sendo essas atividades adquiridas através de um processo de aprendizagem e transmitidas ao conjunto de seus membros.” (p. 120). Evidencia-se nessa definição a importância dada à aprendizagem que ocorre entre os membros do grupo, geralmente de geração em geração.

Assim, no âmbito do grupo GEPEPUCRS, tornou-se relevante adotar um pensamento comum, considerando cultura como o conjunto de todos saberes e fazeres que possuem características próprias de um grupo, seja ele étnico, social ou laboral, e que são gerados e organizados no interior do próprio grupo cultural, geralmente transmitidos de geração em geração.

São com essas perspectivas teóricas que as primeiras pesquisas dos participantes do grupo GEPEPUCRS foram orientadas e delineadas. Contudo, algumas movimentações e deslocamentos foram feitos, principalmente, ao perguntar sobre as condições que possibilitaram a legitimação de determinados saberes em detrimento a outros e perceber que estudantes da Educação Básica são subjetivados de um determinado modo e não de outro, atravessados por relações de poder e saber. A busca por possíveis respostas fez com que as discussões avançassem em relação aos estudos foucaultianos, em particular acerca da relação poder e saber ${ }^{15}$ e dos mecanismos de controle, bem como atentar sobre questões da "virada linguística" e jogos de linguagem abordadas por Wittgenstein em sua segunda fase. Efeito desse movimento, foram novos direcionamentos dados às leituras e investigações do grupo.

Além de continuar considerando os saberes matemáticos presentes nas práticas de pessoas com baixa escolarização ou que possuem profissões nas quais se utilizam de ideias não consideradas como matemáticas, novas pesquisas começaram a ser desenvolvidas tendo como foco, por um lado as relações de poder envolvidas em tramas históricas que fizeram determinados saberes serem marginalizados e, por outro lado, as diferentes formas de uso

15 "O poder deve ser analisado como algo que circula, ou melhor, como algo que só funciona em cadeia. Nunca está localizado aqui ou ali, nunca está nas mãos de alguns, nunca é apropriado como uma riqueza ou um bem. O poder funciona e se exerce em rede. Nas suas malhas, os indivíduos não só circulam mas estão sempre em posição de exercer este poder e de sofrer sua ação[...].” (FOUCAULT, 1989, p. 183).

ISSN 2526-2882 
dados à Matemática presentes em distintas formas de vida analisando os jogos de linguagem constituídos pelas diferentes práticas discursivas.

Para Wittgenstein a noção de uso é essencial para compreendermos a concepção de linguagem e tal uso é relacionado pelo filósofo ao conceito de significação. Assim, se em sua primeira fase, em sua obra Tractatus, significação era concebido como a "denotação de um objeto", em Investigações, Wittgenstein afirma que a significação é determinada pelo uso que se faz das palavras na linguagem de origem de cada grupo, ou seja, em diferentes contextos e situações. Assim, o autor substitui o sentido pragmático dado às significações linguísticas, assumindo um sentido semântico. Conforme Wittgenstein:

Para uma grande classe de casos - mesmo que não para todos - de utilização da palavra "significado", pode-se explicar essa palavra do seguinte modo: $\mathrm{O}$ significado de uma palavra é seu uso na linguagem. E o significado de um nome se explica, muitas vezes, ao se apontar o seu portador. $(2014, \S 43$, p. 38 , grifos do autor).

A "virada linguística" mostra que não existe nada fora da linguagem, assim, Wittgenstein (2014) nega a existência de uma linguagem universal. Tanto a linguagem quanto o discurso produzem a realidade podendo ser relativizados. O filósofo relaciona os jogos de linguagem às formas de vida, afirmando: "E representar uma linguagem equivale a representar uma forma de vida.” (§19, p. 23). Complementa: “Chamarei de ‘jogos de linguagem’ também a totalidade formada pela linguagem e pelas atividades com as quais ela vem entrelaçada.” (2014, §7, p. 19). Nesse sentido, o termo "jogo de linguagem” significa que “[...] falar uma língua é parte de uma atividade ou de uma forma de vida.” (WITTGENSTEIN, 2014, §23, p. 27).

Em estudos mais atuais, Knijnik (2004) passa a tratar a Etnomatemática como um campo, alicerçando-se teoricamente nos estudos de Foucault e nas ideias do Segundo Wittgenstein para definir a Etnomatemática como uma "caixa de ferramentas teóricas". Ao tratar a Etnomatemática a partir dos jogos de linguagem, Knijnik et al. (2012) afirmam ser possível "[...] que se compreendam as matemáticas produzidas por diferentes formas de vida como conjuntos de jogos de linguagem que possuem semelhanças entre si. Assim, não há superconceitos que se pretendam universais e que possam servir como parâmetros para outros." (p.31).

Segundo Bello (2010, p. 565): "Numa perspectiva foucaultiana, a sala de aula apresenta-se como um laboratório de poder, possibilitando recorrentemente a produção e reatualização de discursos e de práticas para o campo da pedagogia.”. Em particular, em relação à disciplina Matemática, Lara (2001) mostra que se trata de "[...] um conjunto de conhecimentos para o controle minucioso do modo de pensar, raciocinar e agir do/a aluno/a e 
que é através da imposição e sujeição a esse modo de pensar, que se produzem determinadas habilidades mentais.” (p. 29). Pois:

A disciplina Matemática exerce seu poder disciplinador por meio de provas graduadas, que abordam conteúdos hierarquizados e determinados por um programa curricular. Através dessas provas, os/as alunos/as são avaliados/as e classificados/as e é, portanto, através delas, que esse poder disciplinador se exerce e transparece, atuando como um olhar que ordena, classifica e normaliza. (LARA, 2001, p. 29).

Ao verificar os programas curriculares de Matemática presente na maioria das escolas, e a concepção que muitos professores possuem da Matemática, mencionado anteriormente, como "[...] uma Matemática exata, pronta, absoluta, universal, a-histórica, atemporal e incontingente, [...].” (LARA, 2001, p. 27), percebe-se o quanto as práticas discursivas presentes no contexto cultural do estudante não são consideradas. Os jogos de linguagem que constam no livro didático - principal instrumento de muitos professores de Matemática - ainda privilegiam as regras presentes na forma de uso da Matemática escolar. Tudo isso acaba reforçando um modelo pedagógico ainda centrado no professor, que embora queira, muitas vezes, tornar o estudante protagonista dos processos de ensino e aprendizagem, acabam por não valorizar diferentes saberes matemáticos que poderiam emergir das diversas formas de vida as quais esses estudantes pertencem por ainda estarem presos à imposição de um determinado modo de pensar matematicamente.

Diante disso tudo, ao considerar a perspectiva d'ambrosiana na qual a Etnomatemática é um programa de pesquisa que possibilita compreender a geração, a organização e a difusão de saberes matemáticos, e fundamentar-se em Wittgenstein, é possível conceituar a Etnomatemática como um método de pesquisa e de ensino que possibilita analisar os diferentes jogos de linguagem presentes nas práticas discursivas de distintos grupos culturais. Tal conceito é adotado pelo grupo GEPEPUCRS.

\section{A etnomatemática como um método de pesquisa e de ensino}

Embora, alguns pós-estruturalistas possam criticar a busca por um método, vale ressaltar que, de acordo com Veiga-Neto "[...] a palavra método deriva das palavras gregas meta - "para além de" - e odos - "caminho", "percurso"; isso é, um método é o caminho que nos leva para um lugar. No nosso caso, para uma abordagem, para um entendimento.” (2009, p. 84) e que "[...] qualquer decisão sobre usar ou não usar tais expressões depende de onde partimos para falar delas." (p.85). Para o autor: "Esforços para delimitar e fixar o que é um método e qual é o melhor método, bem como o que é uma teoria e quais são os seus limites, 
mostraram-se tão mais infrutíferos quanto mais genéricas e universais eram pensadas as abrangências desses conceitos.” (VEIGA-NETO, 2009, p. 86).

O autor afirma que: "Mesmo que, para algumas perspectivas epistemológicas, método e teoria ainda pareçam assumir um caráter um tanto rígido, prescritivo e formal, não há dúvida de que para muitas outras perspectivas, ocorreu uma flexibilização e uma abertura em ambos." (p.87). Contudo, Veiga-Neto ressalta que tal flexibilização não diz respeito "ao vale tudo" ou "com a ausência de rigor". Conforme o autor, Foucault afirma que não existe mais a segurança prevista no método cartesiano, pois nada mais é seguro ou previsível: "[...] nem os pontos de saída, nem o percurso, nem os pontos de chegada. [...] não há um solo-base externo por onde caminhar, senão que, mais do que o caminho, é o próprio solo sobre o qual repousa esse caminho é que é construído durante o ato de caminhar.” (2009, p. 89). Com essa perspectiva não busco apontar um método que sirva como um "manual para o professor" ou como "medida-padrão-modelo-gabarito". O que pretendo é seguir a sugestão de Veiga-Neto tomando o termo método em seu sentido mais amplo/soft, flexibilizando-o, tratando-o como na perspectiva foucaultiana: como "uma atividade", uma "maneira de entender", um "modo de ver as coisas".

Vale ressaltar, que, embora refira-me a um método de pesquisa e ensino, considero subliminar o processo de aprendizagem, uma vez que o que se propõe é o protagonismo do estudante. Ao percorrer as etapas desse método, o estudante será o próprio pesquisador, resolvedor do problema, que, em busca de soluções, andará e retornará nessas e a essas etapas, tornando a pesquisa uma atitude cotidiana.

Para tanto, como ponto de partida utilizo alguns dos passos que a Etnomatemática seguiria como recurso pedagógico na aprendizagem, sugeridos por Ferreira (2003), sejam eles: Contexto Social $\rightarrow$ Etnografia $\rightarrow$ Etnologia $\rightarrow$ Modelo $\rightarrow$ Solução/Não-Solução $\rightarrow$ Validação.

Para aprofundar os termos etnografia, etnologia e antropologia, tomo emprestados alguns conceitos do antropólogo Levi-Strauss (1970): a etnografia diz respeito "[...] aos primeiros estágios da pesquisa: observação e descrição, trabalho de campo"; a etnologia, relacionada à etnografia, é "[...] um primeiro passo em direção à síntese”; a antropologia é “[...] uma segunda e última etapa da síntese, tomando por base as conclusões da etnografia e da etnologia." (p. 377). Complementando essa ideia, a etnologia é "[...] um primeiro nível de abstração: analisando os materiais colhidos, fazer aparecer a lógica específica da sociedade que se estuda." (LAPLANTINE, 2007, p. 25). Enquanto a antropologia: "Consiste em um segundo nível de inteligibilidade: construir modelos que permitam comparar as sociedades entre si." (LAPLANTINE, 2007, p. 25). 
É possível fazer uma analogia, dessas três etapas apresentadas por Ferreira (2003) com três das faculdades ou capacidades que, segundo Immanuel Kant ${ }^{16}(1781)^{17}$, constituem a mente enquanto aparato representacional, sejam elas: a faculdade de intuir; a faculdade do entendimento; a faculdade de julgar. Na perspectiva kantiana, a intuição é o meio pelo qual o conhecimento se relaciona aos objetos. Porém, a intuição só tem lugar "[...] na medida em que o objeto nos é dado; [...] caso afete a nossa mente de um certo modo.” (KANT, 2015, p. 71). À capacidade de receber representações por meio do modo como os objetos nos afetam, Kant (2015) denomina sensibilidade. Segundo o filósofo: “Os objetos nos são dados, assim, por meio da sensibilidade, e apenas ela nosfornece intuições; eles são pensados, porém, por meio do entendimento, e deste surgem os conceitos.” (p. 71).

Kant diferencia representações empíricas e puras denominando fenômeno como sendo o “[...] objeto indeterminado de uma intuição empírica [...]" (2015, p. 71), enquanto nas puras não existe nada que pertença à sensação. Trata-se de conhecimentos empíricos, quando existe a presença real do objeto, portanto, sensações; e conhecimentos puros, quando nenhuma sensação se mistura à representação.

Apenas a intuição empírica é insuficiente, pois segundo Kant (2015), dela jamais poderia emergir uma "proposição universalmente válida" e muito menos convincente, pois “[...] mesmo que se pudesse ver através daquele (o fenômeno) até o seu fundo, permanece infinitamente distinta do conhecimento do objeto em si mesmo.” (p. 88). Diante disso, evidencia-se uma diferença entre sensibilidade e intelecto. Quando ficamos ao nível da primeira, o objeto representado possui apenas uma constituição subjetiva a qual constitui sua forma como fenômeno, trata-se de uma disposição particular de um determinado sentido.

É possível afirmar, em uma perspectiva wittgensteineana, que tal intuição empírica só tem sentindo no uso que se faz do objeto naquela forma de vida. Ou seja, a compreensão do fenômeno, só se tornaria possível a partir da compreensão das regras que compõem os jogos de linguagem utilizados naquela forma de vida.

Vale ressaltar aqui, que por mais estranheza que possa causar ao tentar articular autores com tradições filosóficas e acadêmicas tão distintas e que viveram em décadas distantes, me parece muito produtivo aproximá-los e buscar por confluências. Muitas vezes, embora algumas coisas já tenham sido ditas, se mudarmos o momento ou contexto em que foram utilizadas, novas lentes poderão ser postas e outras condições serão dadas para que se identifique outros possíveis e diferentes usos tanto desses ditos como daquilo que não foi dito.

${ }^{16}$ Immanuel Kant (1724-1804).

17 Vale ressaltar que a primeira edição da Crítica da razão pura, foi publicada em 1781 . A primeira tradução para a língua portuguesa foi em 1959 e para este texto utiliza-se a $4^{\mathrm{a}}$ edição da tradução e notas de Fernando Costa Mattos. ISSN 2526-2882 
Kant (2015) chamou de entendimento a "[...] faculdade de reproduzir representações por si mesma, ou a espontaneidade do conhecimento." (p. 96, grifos do autor). Trata-se da "[...] faculdade de pensar o objeto da intuição sensível [...].” (p. 96, grifos do autor). Contudo, ambos, sensibilidade e entendimento, são fundamentais para Kant (2015), pois: "Sem sensibilidade nenhum objeto nos seria dado, e sem entendimento, nenhum seria pensado. Pensamentos sem conteúdo são vazios, intuições sem conceitos são cegas.” (p. 96-97). Ou seja: "O entendimento não pode intuir nada, e os sentidos nada podem pensar. Somente na medida em que eles se unifiquem pode surgir o conhecimento.” (p. 97).

Nesse ponto, Kant (2015) distingue a ciência das regras da sensibilidade - a estética -, da ciência das regras do entendimento - a lógica. Para o autor, a lógica tem um duplo sentido: lógica do uso universal que se aplica sem o uso do entendimento, não levando em conta a diversidade dos objetos ao qual se dirige; lógica do uso particular, aquela apresentada na escola, constituída pelas regras que servem para pensar corretamente sobre determinado objeto. Ou seja, percebe-se aqui, os diferentes usos que se pode fazer de um mesmo objeto, cujos jogos de linguagem que o representam possuem suas próprias regras de entendimento, como se fossem a lógica do uso particular que ele delineia dentro de uma determinada forma de vida. Finalmente, Kant (2015) explica o entendimento por meio da espontaneidade do conhecimento, opondo-o à receptividade da sensibilidade, por meio de uma faculdade do pensar, faculdade dos conceitos, faculdade dos juízos. Assim: "A sensibilidade nos dá forma (da intuição), o entendimento nos dá regras.” (p. 168).

Diante disso, a etnografia se assemelha ao momento da intuição, onde são percebidos os usos que uma determinada forma de vida faz de um objeto ou de uma palavra. Será por meio da etnologia, que se criarão condições para reconhecer e entender as regras que definem o jogo. Conforme Wittgenstein (2014, p. 123): “As palavras desta linguagem devem relacionar-se com o que só quem fala pode saber; isto é, com suas sensações imediatas e privadas. Portanto, outra pessoa não pode entender esta linguagem.”, a menos que seja capaz de compreender a relação entre o pensamento e o indivíduo que pensa, como ele usa os signos, as palavras, ou seja, quais seus jogos de linguagem e que regra os descrevem. Faz-se necessário examinar de que modo essas formas de linguagem emergem reconhecendo semelhanças e dessemelhanças com outras formas de linguagem mais ou menos complexas. Assim: "Apercebemo-nos da possibilidade de construir as formas complicadas pela adição gradual de novas formas a partir das formas primitivas." (WITTGENSTEIN, 1958, p, 47).

Com esses pressupostos, criam-se condições para apresentar com outras lentes as três etapas de Ferreira ao apontar a Etnomatemática como recurso pedagógico.

A primeira: etnografia - intuição, percepção, hipóteses; para Kant a mente percebe algo por meio das sensações - intuições, relacionadas à sensibilidade e apreensão do objeto 
obtida por meio dos sentidos -, qualidades inerentes à experiência, e precisa organizar todo o material, os dados, os fatos percebidos, realizar uma primeira síntese, de tal modo que crie condições para apreensão dos mesmos (KANT, 2015). Ou seja, perceber os jogos de linguagem que estão sendo utilizados e quais as regras que o definem a partir do uso que está sendo feito de determinado objeto ou palavra dentro daquela forma de vida, perceber as relações entre os indivíduos que pensam e como pensam, identificando como eles operam com as palavras, criando hipóteses em relação as suas palavras, seus gestos, seus contextos. Enfim, percebe de que modo aquela forma de vida está atravessada em relações sociais e de poder.

A segunda: etnologia - compreensão, entendimento; para compreender a realidade experimentada é necessário que haja entendimento. Pois as intuições, em um primeiro momento, são apenas hipotéticas e precisam da imaginação, e Kant afirma a necessidade de vincular a essas imagens criadas conceitos. Assim, define o entendimento como a faculdade de regras, o modo como os objetos são pensados nos conceitos. Os conceitos são classificados como empíricos ou puros, sendo que este último se utiliza apenas do intelecto. De acordo com Freitas (2017),

[...] para fazer a síntese intelectual precisamos conectar dois planos cognitivos radicalmente distintos: aquele ligado à concretude específica e única de uma imagem e uma regra abstrata, genérica, e que muitas vezes se apóia em noutras regras também complexas e que são aplicáveis indefinidamente a um número infinito de casos possíveis. (p. 10).

É o entendimento que irá produzir e articular conceitos. Kant afirma tratar-se de duas habilidades distintas: “[...] a de poder raciocinar através de princípios gerais, abstratos, e a de saber operar com eles na realidade, aplicá-los nos casos específicos, fazendo uma leitura das circunstâncias particulares e a partir deles.” (FREITAS, 2017, p. 11). Trata-se de identificar e compreender as regras que definem os jogos de linguagem utilizados verificando seus graus de parentescos com outros jogos utilizados em outras formas de vida.

A terceira: validação da solução/modelo - julgamento; considerando que, na perspectiva kantiana, o juízo envolve conceitos responsáveis pela ordenação, unificação e síntese dos dados em uma representação comum. Para determinar se algo está ou não de acordo com determinada regra, é estabelecido o julgamento, ou seja, a subsunção sob regras. De acordo com Freitas (2007):

Assim, para a síntese intelectual ocorrer, é necessário o concurso de uma terceira faculdade, além da imaginação e do entendimento, e que exprime uma habilidade própria do ser humano, que é a nossa capacidade de julgar os fatos particulares a partir de conceitos universais, produzindo uma interpretação de mundo. (p. 11). 
Contudo, de acordo com Kant (2015), "[...] embora o entendimento possa ser ensinado e abastecido por meio de regras, a faculdade de julgar é um talento especial que certamente não pode ser ensinado, mas tem de ser exercitado.” (p. 172). Para o filósofo, a escola até consegue "encher" os estudantes com entendimento limitado de regras, porém para utilizar corretamente esse entendimento é necessária uma faculdade própria ao estudante. Assim: “A ausência da faculdade de julgar é, de fato, aquilo a que se chama burrice, e tal deficiência não pode ser sanada." (p. 173).

É nesse sentido, fazendo uma aproximação entre as ideias de Wittgenstein, Ferreira e Kant, que defino a Etnomatemática como um método de ensino capaz de se guiar pelas três seguintes etapas ${ }^{18}$ :

$1^{\text {a }}$ etapa) Etnografia - sensibilização/apreensão: corresponde, na maioria das vezes, a uma etapa de cunho etnográfico na qual o estudante estabelece uma conexão com o grupo ou membros do grupo que será investigado, buscando, direta ou indiretamente, levantar dados inerentes aos saberes culturais, saberes matemáticos, desse grupo em relação aos seus saberes e fazeres e suas formas de vida. Além disso, é possível, por meio de observações, entrevistas e narrativas, perceber os jogos de linguagem que estão presentes nas práticas discursivas hegemônicas das formas de vida estudada. É o momento que, por meio de sua intuição/imaginação levanta suas hipóteses e apreende a realidade investigada.

$\mathbf{2}^{\mathbf{a}}$ etapa) Etnologia - compreensão/entendimento: para que seja possível que faça emergir a lógica presente no grupo estudado, o estudante necessita racionar por meio dos princípios gerais, abstratos apresentados pelo professor acerca dos possíveis conceitos matemáticos envolvidos nos saberes matemáticos percebidos durante a primeira etapa, para que seja capaz de articular tais conceitos à realidade investigada buscando refletir acerca de conceitos particulares e sua aplicabilidade em determinadas formas de vida. É o momento em que entende a realidade experimentada buscando vincular as hipóteses levantadas, acerca dos saberes matemáticos percebidos e dos jogos de linguagem retirados do uso que os pesquisados faziam desses saberes, aos conceitos apresentados pelo professor, presente nos jogos de linguagem apresentados pela Matemática Escolar. Intenciona-se a identificação e a determinação de regras.

\footnotetext{
18 Vale sublinhar que a palavra etapa, assim como a palavra método, adquire, neste estudo, o significado que lhe será dado a partir do uso que se fará dela. As etapas são vistas como necessárias, não apenas pela sugestão de Ferreira, mas pela necessidade de perceber ( $1^{\mathrm{a}}$ etapa), compreender ( $2^{\mathrm{a}}$ etapa) e interpretar ( $3^{\mathrm{a}}$ etapa) os jogos de linguagem presentes em determinada forma de vida.
} 
$3^{\mathbf{a}}$ etapa) Validação - interpretação/julgamento: nessa etapa os estudantes, com base nos conceitos abordados pelo professor, refletirão sobre os saberes matemáticos apresentados pelo grupo estudado, percebendo semelhanças de família entre os jogos de linguagem em seus diferentes usos, tanto aqueles apresentados pelo grupo cultural quanto aquele eleito como legítimo no âmbito da sala de aula. O que se propõem é que os estudantes, diante das regras identificadas na etapa anterior, possam analisar, caso existam, os limites de seu uso dentro de cada forma de vida, reconhecendo que esses saberes produzidos por diferentes práticas discursivas podem ser vistos como formas de conhecimento. É possível, nessa etapa, validar modelos construídos com base nas duas primeiras etapas.

Ao sugerir essas etapas, visualiza-se o estudante como protagonista do processo de aprendizagem. Verifica-se que as etapas são eficazes para evidenciar a Etnomatemática como um método de pesquisa, uma vez que se faz necessário que o estudante vá a campo tornandose o pesquisador. Por outro lado, para a compreensão e entendimento, os processos de ensino e de aprendizagem deverão ser operacionalizados pelo professor, constituindo a Etnomatemática como método de ensino.

Pensando nessas etapas, a Etnomatemática configura-se como um método de ensino que pode ser utilizado tanto na Educação Básica, como no Ensino Superior. Vale ressaltar que esse movimento é cíclico à medida que precisará, uma vez que sua validação não seja sólida, retornar às hipóteses levantadas por meio dos dados coletados ou ao entendimento que tiveram sobre a realidade estudada. Ou seja, por vezes será necessário que o professor solicite aos estudantes que retornem aos estudos etnográficos e etnológicos, para reforçar o processo de validação.

\section{Nossas pesquisas}

Desde 2012, no âmbito do grupo de estudos GEPEPUCRS, algumas investigações vêm sendo desenvolvidas com o objetivo de apontar diferentes possibilidades acerca da operacionalização da Etnomatemática como método de pesquisa e de ensino na Educação Básica, por meio do reconhecimento de jogos de linguagem que constituem diferentes saberes matemáticos. A partir de então, foram concluídas dez pesquisas desenvolvidas no curso de Mestrado do Programa de Pós-Graduação em Educação em Ciências e Matemática - da PUCRS, sob orientação da autora. Apresenta-se, no Quadro 1, informações sobre cada uma delas. 
Quadro 1 - Dissertações orientadas no âmbito do grupo GEPEPUCRS

\begin{tabular}{|c|c|c|c|}
\hline Ano & Título & Autor & Orientadora \\
\hline 2014 & $\begin{array}{l}\text { D1 - Aprendizagem da geometria: a } \\
\text { emática como método de ensino }\end{array}$ & $\begin{array}{l}\text { Eliane Maria } \\
\text { Hoffmann Velho }\end{array}$ & \multirow{10}{*}{ 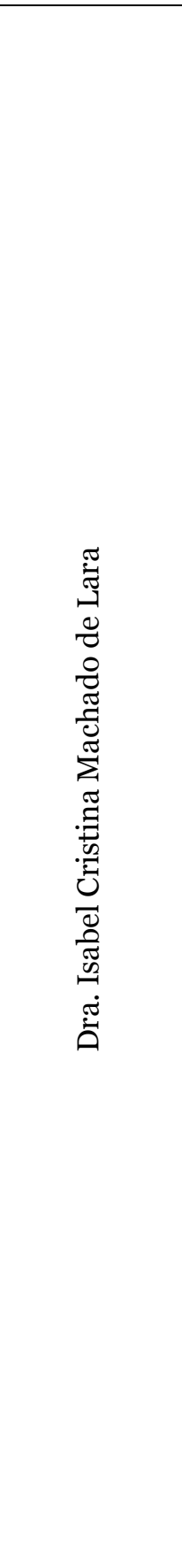 } \\
\hline 2015 & $\begin{array}{l}\text { D2 - Histórias de pescadores : uma } \\
\text { etnomatemática sobre os saberes da pesca } \\
\text { l da Ilha da Pintada - RS }\end{array}$ & $\begin{array}{l}\text { Mayara de } \\
\text { Araújo } \\
\text { Saldanha }\end{array}$ & \\
\hline 2015 & $\begin{array}{l}\text { D3 - Etnomatemática e relações de poder: } \\
\text { lise das narrativas de colonos descendentes } \\
\text { les da região do Vale do Rio dos Sinos }\end{array}$ & Ketlin Kroetz & \\
\hline 2016 & $\begin{array}{l}\text { D4 - A construção de "caixas" de } \\
\text { xo na comunidade quilombola do Curiaú: } \\
\text { rdagem etnomatemática }\end{array}$ & $\begin{array}{l}\text { Quele Daiane } \\
\text { Ferreira } \\
\text { Rodrigues }\end{array}$ & \\
\hline 2019 & $\begin{array}{l}\text { D5 - Diferentes usos da matemática: uma } \\
\text { dade da etnomatemática como método de }\end{array}$ & $\begin{array}{l}\text { Luis } \\
\text { Tiago Osterberg }\end{array}$ & \\
\hline 2019 & $\begin{array}{l}\text { D6 - Possibilidades para a etnomatemática } \\
\text { hétodo de ensino: analisando jogos de } \\
\text { m presentes em diferentes profissões }\end{array}$ & $\begin{array}{l}\text { Gisella de Souza } \\
\text { Ferreira }\end{array}$ & \\
\hline 2018 & $\begin{array}{l}\text { D7 - Ensino da matemática na educação } \\
\text { uma análise das percepções de professores } \\
\text { gos de linguagem presentes em sua prática }\end{array}$ & $\begin{array}{l}\text { Luciane } \\
\text { Santorum } \\
\text { Fredrich }\end{array}$ & \\
\hline 2015 & $\begin{array}{l}\text { D8 - Saberes etnomatemáticos na } \\
\text { de professores indígenas do curso de } \\
\text { ura intercultural na Amazônia }\end{array}$ & $\begin{array}{l}\text { Jonatha Daniel } \\
\text { do Santos }\end{array}$ & \\
\hline 2015 & $\begin{array}{l}\text { D9 - Produções brasileiras sobre } \\
\text { emática no século XXI: uma análise das } \\
\text { ões da concepção de etno e cultura }\end{array}$ & $\begin{array}{l}\text { Renata Vieira } \\
\text { dos Santos }\end{array}$ & \\
\hline 2016 & $\begin{array}{l}\text { D10 - Uma abordagem etnomatemática } \\
\text { implicações dos números no Batuque do } \\
\text { de do Sul }\end{array}$ & $\begin{array}{lr}\text { Jackson } & \text { Luís } \\
\text { Santos } & \text { de } \\
\text { Vargas } & \end{array}$ & \\
\hline
\end{tabular}

Fonte: a autora

Dessas produções foram escolhidas para compor o corpus deste estudo, as seis primeiras cujas temáticas vão ao encontro do objetivo deste texto: a aprendizagem da geometria por meio dos saberes matemáticos de um marceneiro; diferentes formas de uso da Matemática desenvolvidos por pescadores artesanais; jogos de linguagens presentes nas práticas discursivas de colonos alemães; uso de saberes matemáticos na confecção de caixas 
(tambores); a aprendizagem do conceito de função no $1^{0}$ ano do Ensino Médio por meio da compreensão dos diferentes jogos de linguagem, evidenciados em distintas profissões; a compreensão de conceitos matemáticos por meio de diferentes formas de uso da Matemática e suas regras e diversas profissões.

Acerca de cada uma das dissertações, realizou-se uma síntese apontando as ideias principais, dando ênfase às possíveis articulações com o ensino da Matemática.

\section{D1 - Aprendizagem da geometria: a Etnomatemática como método de ensino. Essa} pesquisa objetivou analisar as contribuições da Etnomatemática como método de ensino para a aprendizagem de geometria e teve como metas específicas: compreender como um saber matemático identificado dentro da comunidade escolar pode ser apreendido e reconstruído pelos estudantes em sala de aula; analisar a fala dos estudantes durante o processo de reconstrução do modelo matemático intrínseco no saber matemático; verificar a contribuição, para a aprendizagem de geometria, do processo de comparação entre o saber do marceneiro e da matemática escolar. Para tanto, a pesquisadora desenvolveu "[...] uma proposta de ensino de geometria estruturada a partir de saberes matemáticos empregados por um profissional da marcenaria evidenciado na comunidade escolar dos estudantes participantes da investigação.” (p. 18). A proposta se estruturou nas três etapas da Modelagem Matemática definidas por Biembengut: Percepção e apreensão; Compreensão e explicação; Representação e modelação, desenvolvida durante 21 horas/aula, com estudantes entre 12 e 15 anos, do $7^{\circ}$ ano do Ensino Fundamental de uma instituição estadual pública, da cidade de Gramado, RS, Brasil. A proposta foi delineada a partir do modelo mental criado por um marceneiro, de 58 anos, que estudou até o $5^{\circ}$ ano do Ensino Fundamental, no desempenho de sua atividade laboral, em particular na confecção de uma estante. O marceneiro, convidado a explicar aos estudantes como se dá a confecção de uma estante, evidenciou que a gama de saberes intrínsecos no desempenho de sua profissão engloba consideráveis ideias matemáticas. Os estudantes foram desafiados à elaboração de um protótipo e a debater sobre os saberes matemáticos empregados pelo marceneiro e os conhecimentos matemáticos tratados na escola. A análise evidencia que a Etnomatemática pode ser vista como método que favorece o ensino da Matemática por meio da interpretação, construção e verbalização do que está sendo estudado, que resulta em uma aprendizagem de cunho crítico em meio à interação sociocultural. Vale ressaltar, que essa foi a primeira pesquisa desenvolvida no âmbito do grupo de pesquisa. Assim, na análise, a autora não se preocupou em dar conta dos jogos de linguagem presentes no discurso do marceneiro. Contudo, são evidentes as semelhanças de família entre os jogos de linguagem da forma de vida do marceneiro e da forma de vida escolar, uma vez que muitos estudantes ao produzirem seus modelos influenciaram-se pelas explicações dadas pelo marceneiro reconhecendo que as 
mesmas noções matemáticas apareciam na fala da professora. O objetivo central foi apontar a Etnomatemática como um método de ensino. As etapas percorridas foram as mesmas da Modelagem Matemática proposta por Biembengut (2016). Essa orientação foi dada por perceber a sua base no modelo cognitivo de Imannuel Kant (1781) e na proposta feita por Ferreira (2003) acerca da Etnomatemática como recurso pedagógico.

\section{D2 - Histórias de pescadores: uma pesquisa etnomatemática sobre os saberes da} pesca artesanal da Ilha da Pintada - RS. O objetivo dessa pesquisa foi apresentar uma análise dos processos de geração, organização e difusão dos saberes utilizados pelos pescadores artesanais da Ilha da Pintada, bairro pertencente ao município de Porto Alegre, RS, Brasil. Realizou um estudo de caso etnográfico, considerando a Etnomatemática como um método de pesquisa, analisou entrevistas semiestruturadas realizadas com três pescadores artesanais. Evidencia que os saberes dos pescadores artesanais "[...] têm sido gerados devido à necessidade de lidar com as distintas situações do dia a dia na pesca artesanal. Indica que a geração dos saberes não está vinculada à frequência escolar." (p.6) e que ocorre por meio das condições possibilitadas em ambientes familiares, sujeitos, à experiência prática. Mostra que a organização dos saberes ocorre “[...] em função das relações sociais e condições ambientais a que estão submetidos esses pescadores e, intelectualmente, por meio da utilização de um modo de pensar e de uma linguagem particular do grupo.” (p. 6). Aponta que a difusão dos saberes está relacionada à otimização dos recursos da pesca bem como à industrialização dos materiais" e "[...] mediante as relações familiares e de compadrio, sendo vistos como um conhecimento patrimonial." (p. 6).

\section{D3 - Etnomatemática e relações de poder: uma análise das narrativas de colonos} descendentes de alemães da região do Vale do Rio dos Sinos. Na mesma direção da pesquisa anterior, essa investigação teve como objetivo identificar e compreender os processos de geração, organização e difusão dos saberes de três colonos descendentes de alemães residentes na região do Vale do Rio dos Sinos, município de Santa Maria do Herval, RS. No entanto, apoiada nos estudos de Foucault acerca do poder e disciplinamento do corpo, por meio de três entrevistas semiestruturadas, a autora realizou uma análise genealógica do discurso considerando as relações de poder presentes em determinados momentos históricos marcados, em particular, pela época de escolarização dos sujeitos e pelos saberes utilizados em suas atividades laborais. A análise das narrativas dos colonos indica, entre outras considerações, que “[...] o ensino foi responsável pela alfabetização dos sujeitos entrevistados, no entanto, seus saberes não foram gerados na escola, mas passados de geração em geração e aprimorados de acordo com sua utilização.” (p. 8). Por meio de suas falas explicitaram que 
"[...] os conteúdos aprendidos na escola eram concebidos como jogos de linguagem marcados pelo formalismo e abstração, que objetivavam ensinar o alfabeto, a leitura, a escrita, decorar a tabuada e, principalmente, estudar a bíblia.” (p. 8). Verifica os diversos saberes apresentados pelos sujeitos como “[...] estratégias de venda e técnicas de explicar e entender a complexidade de situações que a vida no campo apresentava, podem ser vistos como jogos de linguagem caracterizados pela oralidade, pensamento proporcional e cálculos aproximados, apresentando pouca semelhança de família com os jogos de linguagem escolares.” (p. 8). Seus saberes são organizados de acordo com suas necessidades e "[...] são difundidos com a utilização de um fator que se encontra na cidade até os dias atuais: a língua alemã.” (p. 8).

\section{D4 - A construção de "caixas" de marabaixo na comunidade quilombola do}

Curiaú: uma abordagem etnomatemática. Com base no Programa Etnomatemática, essa pesquisa objetivou analisar o modo como foram gerados, organizados e difundidos os saberes matemáticos envolvidos na confecção de "caixas" de Marabaixo na comunidade quilombola do Curiaú, localizada no Município de Macapá, AP, Brasil. Por meio de observação da confecção da "caixa” e de entrevistas semiestruturas realizadas com três artesãos pertencentes à comunidade, mostra que os saberes gerados na confecção das "caixas" emergiram a partir da preocupação de um participante ativo da comunidade em conservar esses saberes, uma vez que não são relacionados ao que é ensinado na escola. A geração ocorre a partir da "observação dos seus antepassados" e dos ensinamentos dentro da comunidade. Trata-se de saberes gerados de pai para filho que vêm se organizando a partir de "[...] influências sofridas no meio político, econômico e cultural, e do aprimoramento da matériaprima para construção das caixas.” (p. 7). Acerca da difusão, a análise mostra que "[...] é realizada a partir da realização de oficinas para popularizar o saber, e também da comercialização das caixas como forma de subsistência.” (p. 7). Com base na lei 10639/2003 que altera a Lei de Diretrizes e Bases (Lei 9394/1966) tornando obrigatório o ensino da História e Cultura Afro-Brasileira no Ensino Fundamental e Médio, verifica-se a viabilidade de difundir a confecção das "caixas” em sala de aula. Durante a análise das entrevistas, fica nítida a semelhança que os jogos de linguagem usados pelos artesãos possuem em relação aos jogos de linguagem presentes na matemática escolar. Assim, a oficina que atualmente é dada fora do âmbito escolar pode ser pensada como um modo de valorizar os saberes matemáticos contidos na cultura quilombola. Nesse caso, a proposta de ensino articularia a Etnomatemática e a Modelagem como métodos de ensino.

\section{D5 - Diferentes usos da matemática: uma possibilidade da etnomatemática como}

método de ensino. A partir de uma proposta de ensino constituída por uma pesquisa ISSN 2526-2882 
etnográfica com trabalhadores pertencentes à comunidade escolar, realizada por 37 estudantes de um $2^{\mathrm{o}}$ ano do Ensino Médio de uma escola pública o pesquisador coletou dados para analisar de que modo o reconhecimento de diferentes usos da Matemática e suas regras modificam como estudantes do Ensino Médio compreendem conceitos matemáticos tendo a Etnomatemática como método de ensino. Utilizou-se de questionários e observações para verificar a percepção dos estudantes acerca da Matemática, de sua importância, e a compreensão dos mesmos em relação aos jogos de linguagem presentes em atividades laborais de trabalhadores pertencentes à comunidade escolar, e para analisar as modificações que o reconhecimento dos jogos de linguagem e das regras de uso desses jogos implicaram no entendimento de conceitos matemáticos. O pesquisador se apoia na perspectiva de D’Ambrosio e de Ferreira sobre Etnomatemática e nos estudos do Segundo Wittgenstein para abordar jogos de linguagem. O pesquisador evidenciou que a utilização de uma proposta pedagógica baseada na Etnomatemática como método de ensino proporciona a visão de outros jogos de linguagem matemáticos próprios de trabalhadores de sua comunidade e que, ao comparar os jogos de linguagem e as regras presentes nas atividades laborais dos trabalhadores envolvidos na pesquisa com os jogos de linguagem da Matemática Escolar, é possível estabelecer semelhanças entre esses jogos e perceber a validade dos saberes matemáticos utilizados por esses trabalhadores. Os resultados da pesquisa mostram uma contribuição positiva da Etnomatemática como um método de ensino para um melhor entendimento de conceitos matemáticos por parte dos estudantes.

\section{D6 - Possibilidades para a etnomatemática como método de ensino: analisando jogos de linguagem presentes em diferentes profissões. Com base nos mesmos} aportes teóricos da dissertação anterior, a autora da D6 desenvolveu uma pesquisa que teve como objetivo analisar de que modo a compreensão dos diferentes jogos de linguagem, evidenciados em distintas profissões, pode contribuir para a aprendizagem de conceitos matemáticos. Em particular, o foco foi o conceito de função abordado em uma turma do $1^{\circ}$ ano do Ensino Médio, utilizando como método de ensino a Etnomatemática. Para a coleta de dados foram utilizados diferentes instrumentos: dois questionários; duas entrevistas, estruturada e semiestruturada; diário de aula analisados por meio da Análise Textual Discursiva. Com os resultados da análise, foi possível perceber que os jogos de linguagem associados às etapas da Etnomatemática como método de ensino demonstraram eficácia para a compreensão por parte dos estudantes de um conceito pelo seu uso na linguagem. Conforme a pesquisadora esse método ampliou a percepção e compreensão dos estudantes quanto ao uso do conceito em diferentes formas de vida. Destaca que a busca por semelhanças e dissemelhanças dentro dos jogos de linguagem dos profissionais criaram condições que possibilitaram aos estudantes 
perceberem a funcionalidade do uso de um conceito dentro de um grupo profissional. Adicionado a isso, pensar na Etnomatemática como problematizadora dos conceitos utilizados pela Matemática Escolar, abre caminhos que possibilitam conexões dos estudantes com seu meio social, e mostra que é possível articular novos métodos que contribuam para a análise do uso de um mesmo conceito em diferentes jogos de linguagem, a fim de compreender não somente a definição de um conceito, mas sim, o seu uso em uma forma de vida.

Os resultados apontados por essas pesquisas criam condições que possibilitam perceber a eficácia da Etnomatemática tanto quanto método de pesquisa como método de ensino. É perceptível o deslocamento que ocorre em relação às perspectivas teóricas que embasam esses estudos. Embora a primeira pesquisa já se utilizasse da Etnomatemática como método de ensino, seu alicerce teórico foi construído apenas com apoio em Ferreira e com sua articulação na Modelagem Matemática. A Etnomatemática considerada como método de ensino, tendo como pano de fundo a teoria wittgensteiniana, começa a ser operacionalizada nos estudos seguintes, em particular nos dois últimos, percorrendo etapas de pesquisa de campo, análise da pesquisa e validação, ou seja, Etnografia - sensibilização/apreensão; Etnologia - compreensão/ entendimento; Validação - interpretação/julgamento.

Assim como a D1, outras pesquisas estão sendo desenvolvidas com essa mesma pretensão, e o que propõe é mostrar que a Etnomatemática pode ser utilizada em sala de aula percorrendo um caminho além da pesquisa, capaz de instigar nos estudantes o interesse por perceber a validade de outros saberes, seja por meio de semelhanças entre diferentes jogos de linguagem ou por meio da construção de modelos advindos da cultura estudada. Isso se explicita principalmente na D5 e na D6.

Em D2, percebe-se uma primeira etapa da pesquisa realizada pela pesquisadora que fornece dados para que se possa questionar: "De que modo os etnosaberes identificados na pesca artesanal podem ser ressignificados pelos estudantes em sala de aula?”. A partir das perspectivas adotadas neste artigo que define a Etnomatemática como método de ensino é possível pensar, no contexto onde D2 foi desenvolvida, em uma proposta, na qual os estudantes poderão ser inseridos no contexto do pescador, ou vice-versa, serão os autores de suas próprias indagações e por meio de observações e questionamentos criarem condições para: na Etapa 1: Etnografia - sensibilização/apreensão: compreender os processos de geração, organização e difusão desses saberes matemáticos; na Etapa 2: Etnologia - compreensão/entendimento: identificar os jogos de linguagem presentes nas práticas discursivas desses pescadores que evidenciem diferentes usos da Matemática compreendendo-os também por meio dos jogos da Matemática Escolar, buscando determinar as regras presentes em ambos os jogos, os jogos de linguagens expressos pelos diferentes usos da Matemática dentro do contexto investigado e 
aqueles que são apresentados pelo livro didático, buscando compreender cada um em sua essência e sentido; na Etapa 3: Validação - interpretação/julgamento: refletir sobre os saberes matemáticos explicitados pelos pescadores identificando semelhanças e dissemelhanças e, diante das regras identificadas na etapa anterior, analisar, caso existam, os limites de seu uso dentro de cada forma de vida. Além disso, nessa última etapa, podem ser validados modelos construídos pelos estudantes com base nas duas primeiras etapas.

É possível, a partir da pesquisa descrita em D3, elaborar uma proposta de ensino semelhante à da pesquisa anterior, criando condições para que os estudantes compreendam os processos de geração, organização e difusão desses saberes matemáticos ou analisar os jogos de linguagem presentes nas práticas discursivas desses colonos identificando as semelhanças de família entre seus saberes e a Matemática Escolar.

A D4, cria condições que possibilitam abordar em sala de aula um assunto que faz parte dos costumes da região e que é conhecido pelos estudantes, porém, não é tratado no âmbito escolar. A Matemática envolvida na confecção das caixas por essa comunidade apresenta jogos de linguagem que podem ser percebidos pelos estudantes ao realizarem, por exemplo, uma Modelagem Matemática envolvendo a confecção das mesmas. Percebe-se que uma proposta de ensino, fruto dessa investigação potencializa as construções teóricas entre Wittgenstein, Kant e Ferreira, uma vez que nitidamente percorreria as etapas propostas pela perspectiva da Etnomatemática como método de ensino.

$\mathrm{Na} 1^{\mathrm{a}}$ etapa: Etnografia - sensibilização/apreensão: os estudantes realizarão uma pesquisa de cunho etnográfico buscando estabelecer uma conexão com o artesão que confecciona a caixa. Por meio de entrevistas e observações buscarão, direta ou indiretamente, levantar todos os dados inerentes aos saberes culturais, saberes matemáticos do artesão presente em seu fazer, naquela forma de vida necessários para confeccionar a caixa. Nessa etapa, por meio de sua intuição/imaginação levantarão suas hipóteses e apreenderão a realidade investigada.

$\mathrm{Na} 2^{\mathrm{a}}$ etapa: Etnologia - compreensão/entendimento: para fazer emergir os saberes matemáticos utilizados pelo artesão, mesmo que este não o reconheça como Matemática, os estudantes estudarão os conceitos matemáticos envolvidos na confecção da caixa utilizando os jogos de linguagem presentes na Matemática Escolar, para que sejam capazes de articular tais conceitos à realidade investigada buscando refletir acerca de conceitos particulares e sua aplicabilidade na forma de vida do artesão, durante a feitura da caixa. Ou seja, identificarão e determinarão as regras sobre, em particular, conceitos de geometria plana e espacial, tanto na realidade experimentada quando na apresentada pela Matemática Escolar. Nessa etapa, os estudantes confeccionarão a caixa, com base nos saberes do artesão ou nos conhecimentos matemáticos explicados pelo professor. 
$\mathrm{Na} 3^{\mathrm{a}}$ etapa: Validação - interpretação/julgamento: os estudantes apresentarão o modelo de caixa confeccionado e refletirão acerca dos saberes matemáticos identificados na feitura daquele modelo, percebendo semelhanças de família entre os jogos de linguagem em seus diferentes usos, e diante das regras identificadas na etapa anterior, possam analisar, caso existam, os limites de seu uso na confecção da caixa ou em outros contextos.

Tanto a investigação apresentada na D5 e na D6, mostram que é possível operacionalizar a Etnomatemática como um método de ensino, seguindo as etapas propostas deste artigo.

\section{Considerações finais}

Todas as produções abordadas neste texto, advindas de pesquisas desenvolvidas durante um curso de Mestrado, no âmbito do grupo GEPEPUCRS, mesmo que ainda não tenham efetivado as propostas de ensino que suscitam, criam condições que possibilitam pensar em um modo de instigar a reflexão dos estudantes acerca de diferentes saberes matemáticos.

No momento em que os estudantes percebem e apreendem as práticas discursivas de determinados grupos culturais, tornam-se capazes de identificar diferentes jogos de linguagem percebendo suas regras, graus de parentesco e semelhança com aqueles estudados em sala de aula, tanto por meio de um estudo etnográfico ou de uma pesquisa.

Além disso, evidencia que ao reconhecer diferentes formas de vidas, com diferentes práticas discursivas, refletindo sobre como foram gerados, organizados e difundidos seus saberes, os estudantes podem perceber os limites das regras que constituem os jogos de linguagem presentes nesses contextos em relação a outros usos que são feitos da Matemática, compreendendo assim a legitimação ou a marginalização desses saberes. A partir de uma postura crítica e problematizadora, o estudante pode trazer à tona o modo como alguns saberes foram sujeitados pelas práticas discursivas da Matemática Escolar, advinda da Matemática Acadêmica. Trata-se de colocar sobre suspeita a imposição de algumas formas de saberes, em particular, de algumas formas de matematizar.

A Etnomatemática, como método de ensino possibilita que o estudante, ao reconhecer diferentes modos de matematizar, compreenda que embora uma forma de vida não utilize jogos de linguagem semelhantes aqueles apresentados pela Matemática Escolar, os jogos presentes em seu contexto desempenham a função de intervir na sua realidade, legitimandoos dentro daquele grupo. Numa perspectiva foucaultiana, trata-se de saberes sujeitados, por serem nesse caso, saberes desqualificados como saberes conceituais, por não serem suficientemente elaborados de acordo com o nível de conhecimento ou da cientificidade requeridos (FOUCAULT, 2010, p. 8). Trata-se, segundo Foucault (2010), do "saber das 
pessoas", um saber particular, local, regional, diferencial, ou que foi sepultado da erudição ou desqualificado pela hierarquia dos conhecimentos e das ciências.

É possível, portanto, criar condições para que o estudante reflita sobre tal sepultamento e desqualificação, se contrapondo aos efeitos de poder de um determinado conhecimento, nesse caso o legitimado pela Matemática Acadêmica, hegemônico dentro das escolas por meio da Matemática Escolar, que impõem um determinado modo de matematizar. A Etnomatemática, nessa perspectiva, pode ser considerada como uma contraconduta capaz de contribuir para reaparição desses saberes, ou nas palavras de Foucault, para insurreição dos saberes sujeitados.

Diante de tudo isso, defende-se a viabilidade de considerar a Etnomatemática como um método de ensino para Educação Básica, que ao percorrer as três etapas propostas neste estudo, pode criar condições que possibilitem aos professores e estudantes refletirem acerca de modos de matematizar que muitas vezes são deixados de lado e desqualificados, mas que podem estar presentes em formas de vida muito próximas à realidade em que estão inseridos.

\section{Referências}

ASCHER, M.; ASCHER, R. Code of the Quipu: a study in media, mathematics and culture. Ann Arbor: The Universityof Michigan Press, 1981.

BARTON, B. Dando sentido a Etnomatemática: Etnomatemática fazendo sentido. IN: RIBEIRO: J. P. M.; DOMITE, M. C. S.; FERREIRA, R. (Orgs.). Etnomatemática: papel, valores e significado. São Paulo: Zouk. 2006.

BELLO, S. E. L. Jogos de linguagem, práticas discursivas e produção de verdade: contribuições para a educação (matemática) contemporânea. Revista Zetetiké. v. 18, p. 545-587, 2010.

CONDÉ, M. L. L. Wittgenstein: Linguagem e Mundo. São Paulo: Annablume. 1998.

. As teias da razão: Wittgenstein e a crise da racionalidade moderna. Belo Horizonte: Argvmentvm. 2004.

D’AMBROSIO, U. Etnomatemática se ensina? BOLEMA, n. 4, v. 3, 1988.

. Etnomatemática: um programa. A Educação Matemática em Revista, Blumenau, v. 1, n. 1, p. 5-11. 1993 .

. Elo entre as tradições e a modernidade. Belo Horizonte, Ed. Autêntica, 2002.

. Um enfoque transdisciplinar à educação e à história da matemática. In: BICUDO, M. A. V.; BORBA, M. C. (Orgs.). Educação Matemática: pesquisa em movimento. São Paulo: Cortez. 2004.

FERREIRA, E. S. O que Etnomatemática. 2003. Disponível In: <http://www.ufrrj.br/leptrans/arquivos/etno.pdf> Acesso em: abril de 2012. ISSN 2526-2882 
FREITAS, V. A formação do conhecimento na Crítica da razão pura, de Immanuel

Kant. Disponível in: <http://www.verlaine.pro.br/txt/ conhecimento-crp.pdf>. Acesso em: junho de 2017.

FOUCAULT, M. Microfísica do poder. 8 ed. Tradução de Roberto Machado.Rio de Janeiro: Graal, 1989.

. Ditos e escritos: estratégia, poder-saber. Rio de Janeiro: Forense Universitária, v. 4, 2003.

. Em defesa da sociedade: Curso do Collège de France (1975-1976). 2. ed. São Paulo: Editora Martins Fontes, 2010.

GEERTZ, C. A interpretação das culturas. Rio de Janeiro: GuanaBará Koogan, 1989.

GERDES, P. Aritmética e ornamentação geométrica: a análise de alguns cestos de índios do Brasil. In: FERREIRA, M. K. L. (Org.) Ideias matemáticas de povos culturalmente distintos. São Paulo: Editora Global, p. 206-220, 2002.

HERSKOVITS, M. J. Antropologia Cultural: Man and his works. São Paulo: Editora Mestre Jou, 1973.

KANT, I. Crítica da razão pura. 4. ed. Petrópolis: Editora Vozes, 2015.

KINIJNIK, G. Exclusão e Resistência: Educação Matemática e Legitimidade Cultural. Porto Alegre: Artes Médicas, 1996.

- Itinerários da Etnomatemática: questões e desafios sobre o cultural, o social e o político na educação matemática. In: KNIJNIK, G.; WANDERER, F., OLIVEIRA, J.

C. Etnomatemática, currículo e formação de professores. Santa Cruz do Sul: EDUNISC, p. 19-37, 2004.

.; WANDERER, F.; GIONGO, I. M.; DUARTE, C. G. Etnomatemática em

Movimento. Belo Horizonte: Autêntica Editora, 2012.

KROETZ, K.; LARA, I. C. M. Jogos de linguagem e formas de vida: um estudo com colonos alemães do vale do Rio dos Sinos. Revista Areté, Revista Amazônica de Ensino de Ciências, Manaus, v. 9, n. 18, p. 244-253, 2016.

LAPLANTINE, F. Aprender Antropologia. São Paulo: Editora Brasiliense, 2007.

LARA, I. C. M. Histórias de um "lobo mau": a matemática no vestibular da UFRGS. 2001. 242f. Dissertação (Mestrado) - Universidade Federal do Rio Grande do Sul, 2001.

LARAIA, R. B. Cultura: um conceito antropológico. 16. ed. Rio de Janeiro: JorgeZahar Ed, 2003.

LÉVI-STRAUSS, C. Antropologia estrutural. Rio de Janeiro, Tempo Brasileiro, 1970.

MONTOITO, R. Educação Etnomatemática: três apropriações da teoria. Educação Matemática em Revista. n. 10, v. 2, 2009, p.73-92. 
PESSANHA, J. A. Filosofia e modernidade: racionalidade, imaginação e ética. Educação \& Realidade, Porto Alegre, v. 22, n. 1, p.13-32, 1997.

ROSA, M; OREY, D. Interlocuções Polissêmicas entre a Etnomatemática e os Distintos Campos de Conhecimento Etno-x. Educação em Revista. Belo Horizonte. v. 30, n. 3, p.63-97, 2014.

VEIGA-NETO, A. Teoria e método em Michel Foucault (im)possibilidades. Pelotas. Cadernos de Educação. v. 34, p. 83 - 94, 2009.

.; NOGUEIRA, C. E. Conhecimento e saber apontamentos para os estudos de currículo. In: SANTOS, L. P. (Org.) Convergências e tensões no campo da formação e do trabalho docente: currículo, ensino de Educação Física, ensino de Geografia, ensino de História, escola, família e comunidade. Belo Horizonte: Autêntica. Belo Horizonte, p. 67-87, 2010.

TYLOR, E. B. Primitive Culture. Londres: John Mursay\& Co, 1871.

WALKERDINE, V. O raciocínio em tempo pós-modernos. Educação \& Realidade, Porto Alegre, v. 20, n.2, p. 207-226, 1995

WITTGENSTEIN, L. Investigações filosóficas. 9. ed. (Tradução Marcos G. Montagnoli). Rio de Janeiro, Petrópolis: Editora Vozes; São Paulo, Bragança Paulista: Editora Universitária São Francisco, 2014.

. O Livro Azul. Rio de Janeiro: Edições 70, 1958.

\section{Biografia Resumida}

Isabel Cristina Machado de Lara: Licenciada em Matemática pela UFRGS/Universidade Federal do Rio Grande do Sul; Mestre em Educação pela UFRGS. Doutora em Educação pela UFGRS. PósDoutorado em Educação em Ciências e Matemática pela PUCRS/Pontifícia Universidade Católica do Rio Grande do Sul. Coordenadora do Grupo de Estudos e Pesquisa sobre Etnomatemática/GEPEPUCRS e do Grupo de Estudos e Pesquisas sobre Discalculia/GEPEDPUCRS

Link Lattes: http://lattes.cnpq.br/8350544815405059

e-mail: isabel.lara@pucrs.br 